\title{
Ultrastructural Studies on Oocyte Development and Vitellogenesis associated with Follicle Cells in Female Scapharca subcrenata (Pelecypoda: Arcidae) in Western Korea
}

\author{
${ }^{\dagger}$ Sung Han Kim \\ Faculty of Applied Bioscience, Kunsan National University, Gunsan 54150, Korea
}

\begin{abstract}
Ultrastructural studies on oocyte development and vitellogenesis in oocytes, and the functions of follicle cells during oogenesis and oocyte degeneration were investigated to clarifyb the reproductive mechanism on vitellogenesis of Scapharca subcrenata using electron microscope observations. In this study, vitellogenesis during oogenesis in the oocytes occured by way of autosynthesis and heterosynthesis. Of two processes of vitellogenesis during oogenesis, the process of endogenous autosynthesis involved the combined activity of the Golgi complex, mitochondria and rough endoplasmic reticulum. However, the process of exogenous heterosynthesis involved endocytotic incorporation of extraovarian precursors at the basal region of the oolema of the early vitellogenic oocytes before the formation of the vitelline coat. In this study, follicle cells, which attached to the previtellogenic and vitellogenic oocytes, were easily found. In particular, the follicle cells were involved in the development of previtellogenic oocytes by the supply of nutrients, and vitellogenesis in the early and late vitellogenic oocytes by endocytosis of yolk precursors. Based on observations of follicle cells attached to degenerating oocytes after spawning, follicles of this species are involved in lysosomal induction of oocyte degeneration for the resorption phagosomes (phagolysosomes) in the cytoplasm for nutrient storage, as seen in other bivalves. In this study, the functions of follicle cells can accumulate reserves of lipid granules and glycogen particles for vitellogenesis from degenerating oocytes after spawning.
\end{abstract}

Key words : Phacosoma japonicus, Oogenesis, Vitellogenesis, Follicle cells

\section{INTRODUCTION}

The ark shell, S. subcrenata, is one of a commercially important edible bivalves in East Asian countries, including Korea, China, and Japan. In Korea, this species is found mainly in silty sand at the intertidal and subtidal zones in the coastal waters of Paenyondo, Kyunggi-do, Korea (Yoo, 1976; Kwon et al., 1993; Min et al., 2004). Due to past over-harvesting, it has been identified as a fisheries resource. For the propagation and reproduction of a living natural resource, above all, it is important to understand the reproductive biology such as reproductive physiology in association with yolk formation (vitellogenesis) during oogenesis and the functions of the follicle cells associated with the resorption of nutrients for vitellogensis of oocyte development of this species. Previously there have been

\footnotetext{
Manuscript received July 22, 2016, Received in revised form August 16, 2016, Accepted September 19, 2016

${ }^{\dagger}$ Corresponding Author : Sung Han Kim, Faculty of Applied Bioscience, Kunsan National University, Gunsan 54150, Korea. Tel. : +82-63-469-1838, Email :w0827@kunsan.ac.kr

This is an Open Access article distributed under the terms of the Creative Commons Attribution Non-Commercial License (http:// creativecommons.org/licenses/by-nc/3.0) which permits unrestricted non-commercial use, distribution, and reproduction in any medium, provided the original work is properly cited.
} 
some studies on aspect of reproduction and ecology in $S$. subcrenata, including aspects of maturation and spawning (Tanaka, 1954), larval development (Yoshida, 1953), propagation (Yoo, 1964), morphological characteristics (Yoo, 1977), spermatogenesis the reproductive cycle and ultrastructural characteristics of mature sperm (Kim et al., 2011). On ecology, its distribution (Kwon et al., 1993; Min et al., 2004) was reported.

Despite this, there are still gaps in our knowledge regarding its reproductive biology. Above all, studies on the process of vitellogenesis by oocyte developmental stages in oocytes during oogenesis, and the functions of the follicle cells associated with the supply of nutrients for oocyte development are required to understand reproductive biology of $S$. subcrenata. In many bivalve species, it is well known that the ovaries contain follicle cells (or auxiliary cells), a kind of accessory cells, that play a role in the storage, and synthesis of yolk precursors during oogenesis (Chung, 2008). Therefore, the purpose of present study is to describe oocyte development, vitellogenesis in the oocyte, and the functions of follicle cells during oogenesis. In addition, the aim of this study is to clarify the reproductive mechanism on vitellogenesis of $S$. subcrenata using cytological methods. The results of ultrastructural studies of the germ cell developments and the functions of the follicle cells of this species will provide important information on its reproductive mechanisms of yolk formation.

\section{MATERIALS AND METHODS}

\section{Sampling}

Female specimens of Scapharca subcrenata were collected monthly in the intertidal and subtidal zones of Paenyondo, Ongin-gun, Inchon, Korea, from January to December, 2008 (Fig. 1). For the electron microscopic observations, the clams were then transported to the laboratory where they were maintained in seawater at $20^{\circ} \mathrm{C}$.

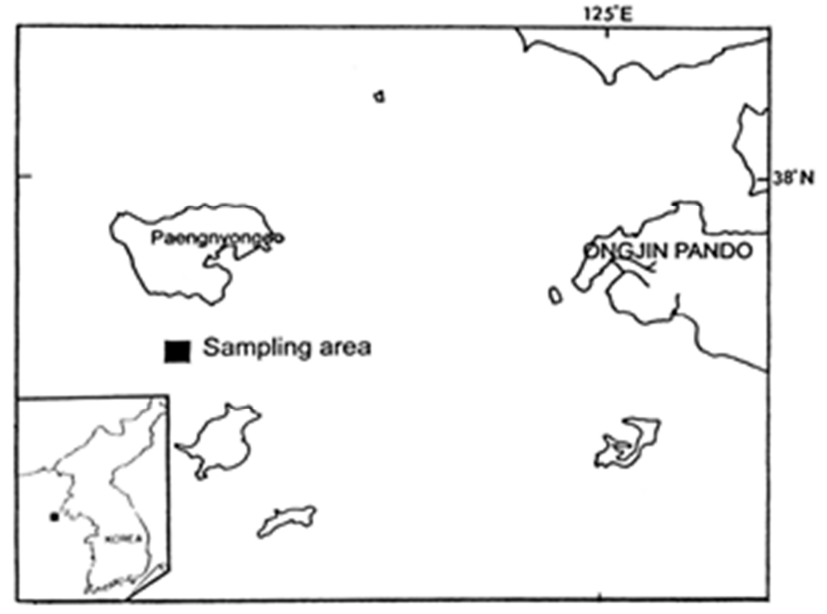

Fig. 1. Map showing the sampling area.

2. Ultrastructure of germ cells and follicle cells during oogenesis

For transmission electron microscope observations, excised pieces of the gonads were cut into small pieces and fixed immediately in $2.5 \%$ paraformaldehyde-glutaraldehyde in $0.1 \mathrm{M}$ phosphate buffer solution $(\mathrm{pH} 7.4)$ for 2 hours at $4^{\circ} \mathrm{C}$ After prefixation, the specimens were washed several times in the buffer solution and then postfixed in a $1 \%$ osmium tetroxide solution in $0.2 \mathrm{M}$ phosphate buffer $(\mathrm{pH}$ 7.4) for 1 hour at $4^{\circ} \mathrm{C}$. Specimens were then dehydrated in increasing concentrations of ethanol, cleared in propylene oxide and embedded in an Epon-Araldite mixture. Ultrathin sections of Epon-embedded specimens were cut with glass knives on a Sorvall MT-2 microtome and LKB ultramicrotome at a thickness of approximately 80-100 $\mathrm{nm}$. Tissue sections were mounted on collodion-coated copper grids, doubly stained with uranyl acetate followed by lead citrate, and observed with a JEM $100 \mathrm{CX}$ - II 80-KV) electron microscope.

\section{RESULTS}

\section{Position and morphology of the ovary}

The ark shell, S. subcrenata, is dioecious organism. The general morphology and internal structure of the ovary of 
this clam are similar to those of other bivalves. The ovary is located between the digestive diverticular and the outer fibromuscular layers, which are compacted by the fibrous connective tissue and muscle fibers. As the ovary matured, it extended to the lowest part of the muscular layers arround the foot. The ovary is a diffused organ consisting of branching follicles containing differentiating oocytes in the various stages. Germ cells are distributed in a centripetal pattern from the follicular wall to the lumen. As ovarian maturation progresses, the external view of the mature ovary is while in color, and the mature testis appear the same white in color. Therefore, the sexes of the clams is hard to distinguish by external features. At this time, if the ovary is slightly scratched with a razor, ripe ova readily flow out; milky white spermatozoa are discharged if the testis is cut.

\section{Ultrastructure of germ cells and follicle cells} during oogenesis

Based on ultrastructural observations, ovarian activity and morphological characteristics of oocytes during oogenesis can be classified into four distinct phases of oogenesis were distingushed in germ cells, that is, (1) oogonia, (2) previtellogenic oocytes, (3) vitellogenic oocytes, and (4) mature oocytes (Eckelbarger \& Davis, 1996). Ultrastructural characteristics in vitellogenesis by each stage of the oocytes, including oocyte degeneration, are as follow:

\section{1) Oogonia}

Commonly, the primary oogonia (about 10-11 $\mu \mathrm{m}$ in diameter) were round or oval in shape. They processed a large ovoid nucleus, in which the chromatin is reticular and marginal. They were found individually or a cluster on the follicular walls. Each primary oogonium contained a nucleolus in the large nucleus, The primary oogonium divided mitotically to produce secondary oogonia. Several mitochondria and vacuoles were present in the cytoplasm of the primary and secondary oogonia. However, vitellogenic characteristics could not be found in this stage because cellular developments of cell organelles in the cytoplasm were very weak (Fig. 2A).

\section{2) Previtellogenic oocytes}

The secondary oogonia developed into previtellogenic oocytes through the first prophase of meiosis. Previtellogenic oocytes were slightly pedunculated, small and oval in shape, commonly they occurred near an oogonium, previtellogenic oocytes and a few vitellogenic oocytes in the oogenic follicle under the photomicrograph (Figs. 2B, 2C). At the beginning of cytoplasmic growth of the previtellogenic oocyte, a large nucleolus in the nucleus was found, and several mitochondria, the rough endoplasmic reticulum, and several vacuoles were concentrated around the perinuclear region in the cytoplasm. During the previtellogenic stage, the nucleus and cytoplasm of the this oocyte increased in volume in this oocyte. The nucleus and oocyte diameters were 4-5 $\mu \mathrm{m}$ and 20-28 $\mu \mathrm{m}$, respectively. However, in this stage, the activity of vitellogenic characteristics in the previtellogenic oocyte showed still weak because yolk materials were not found by cell organelles in the cytoplasm. At this time, in particular, follicle cells measuring 6-8 $\mu \mathrm{m}$ in diameter were attached to each of previtellogenic oocyte. In particular, electron dense marginal chromatin materials appeared in the nucleus, and rough endoplasmic reticulum and several mitochondria were present in cytoplasm of the follicle cell. Progressively the oocyte was surrounded with the follicle cells. Thereafter, the follicle cells attaching to the previtellogenic oocyte were gradually enlarged, and possessed a dense marginal chromatin in the nucleus, and contained rough endoplasmic reticulum, the Golgi complexes and several mitochondria in the cytoplasm (Fig. 2C).

\section{3) Vitellogenic oocytes}

As the further development of previtellogenic oocytes 


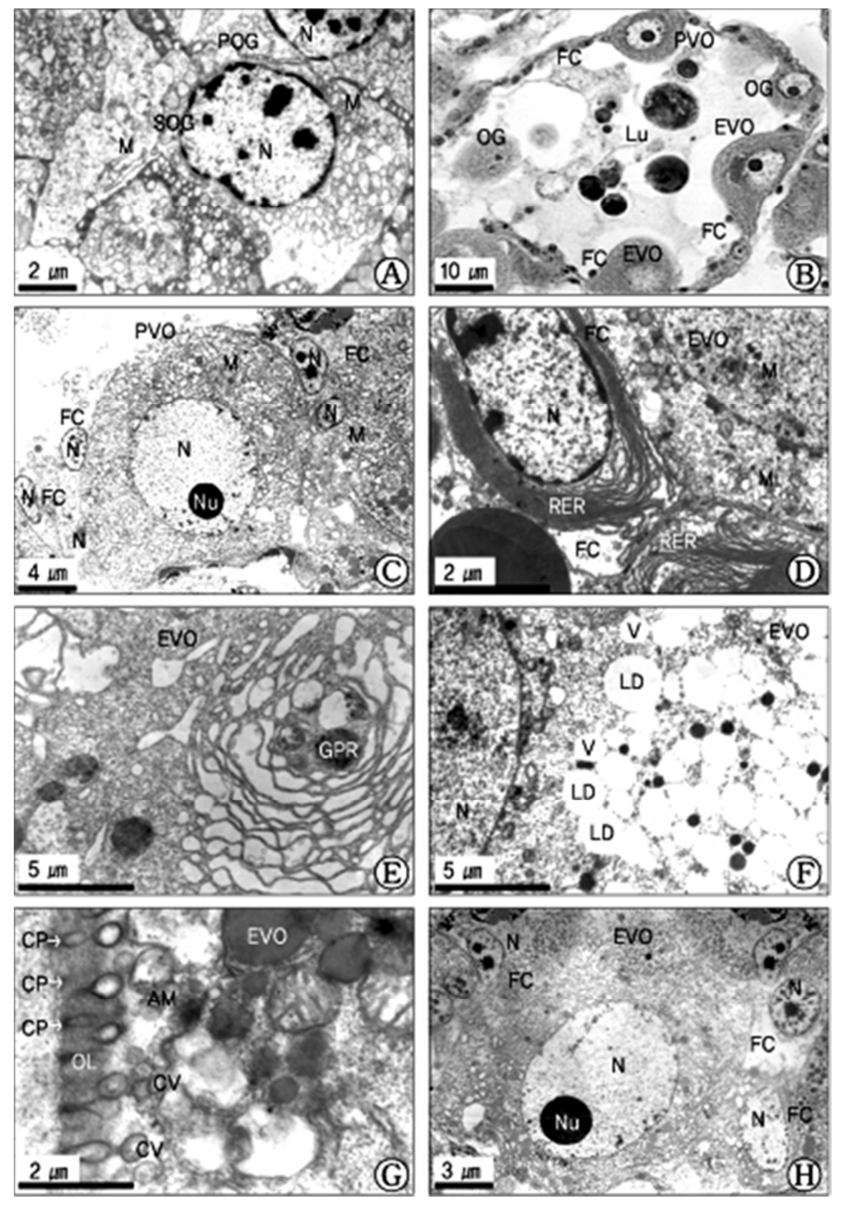

Fig. 2. Electron micrographs showing oogenesis of Scapharca subcrenata (A-H). A, The primary and secondary oogonia in the oogonial phase, with large nucleas, several mitochondria in the cytoplasm; B, A photomicrograph of oogenic follicle, with oogonia, previtellogenic oocytes, early vitellogenic oocytes, follicle cells in the ovary. C, A Previtellogenic oocyte with a nucleolus in the nucleus and several mitochondria in the cytoplasm several follicle cells attaching to a previtellogenic oocyte, D, an early vitellogenic oocyte and the attached follicle cells, with an nucleolus in the nucleus, mitochondria, lipid droplets rough endoplasmic reticulum in the cytoplasm of the oocyte; E, the same stage oocyte, with the Golgi complex containing the Golgi product; F, An eariy vitellogenic oocytes, with several vacuoles and several lipid droplets in the vacuoles; G, An early vitellogenic oocytes, with the coated vesicles formed through the coated pits by endocytosis at the basal region of the oolemma; $\mathrm{H}$, An coated pits by endocytosis at the basal region of the oolemma; $\mathrm{H}$, An early vitellogenic oocytes, with the detached follicle cell (containing a number of vacuoles and myelin-like bodies). Abbreviations: AM, amorphous material, $\mathrm{CP}$, coated pit, $\mathrm{CV}$, coated vesicle; EVO, early vitellogenic oocyte, FC, follicle cell, GPR, golgi product; LD, lipid droplet; M, mitochondria, $\mathrm{N}$, nucleus; NU, nucleolus, OG, oogonium; OL, oolemma, POG, primary oogonium; PVO, previtellogenic oocyte; RER, rough endoplasmic reticulum; SOG, secondary oogonium, V, vacuole.

proceeded, the oocytes developed into vitellogenic oocytes by the meiotic division. At this stage, for convenience, the vitellogenic oocyte can be divided into two vitellogenic oocytes: (1) the early vitellogenic, and (2) late vitellogenic oocytes.

\section{4) Early vitellogenic oocytes}

At this stage, the oocytes (approximately 28-35 $\mu \mathrm{m}$ in diameter) continued to grow and differentiated. The Golgi complexes and clusters of small mitochondria appeared distributed throughout the cytoplasm. The each early vitellogenic oocyte was oval in shape, with the initiation of yolk formation, several vacuoles and mitochondria appeared near the endoplasmic reticulum and the Golgi complex which were present in the perinuclear region in the cytoplasm of the early vitellogenic oocyte. At this time, the follicle cell, which was attached to the early vitellogenic oocyte, contained well-developloped endoplasmic reticulum. A part of early vitellogenic oocyte were partially surrounded by the follicle cells that maintained intimate contact with its smooth oolemma. At the start, the occurrence of the follicle cell was restricted to the stalk region the remains devoid of vitelline envelope material. At this time, each follicle cell possessed dense chromatin and marginal chromatin in the nucleus, and contained mitochondria, glycogen particles and lipid droplets in the cytoplasm (Fig. 2D). At the same time, a number of vacuoles and the Golgi products produced 
by the Golgi complex appeared in the cytoplasm of the early vitellogenic oocytes (Fig. 2E). A number of lipid droplets were accumulated in the vacuoles (Fig. 2F). Formation of the vitelline envelope began in the early stage of vitellogenesis. When the early vitellogenic oocytes began to form microvilli on the oolemma, the initial contours of the microvilli were oval or slightly elongated in shape. Several coated vesicles were present due to endocytosis, and appeared at the basal region of the oolemma of the oocyte. The uptake of exogenous nutritive materials in the coated vesicle formed by receptormediated endocytosis appears through the formation of coated pits on the oolemma during vitellogenesis. At this time, amorphous materials that comprise the vitelline coat are deposited near the cortical region by exocytosis, and the microvillous borders then form on the oolemma (Fig. $2 \mathrm{G})$. As the further development of early vitellogenic oocytes proceeded, several follicle cells were attached to an early vitellogenic oocyte. At this time, the attaching locations of the follicle cells were from the mid part to the upper part of early vitellogenic oocytes. And the ultrastructures of the follicle cells and activity of their cells were relatively active (Fig. 2H).

In the early vitellogenic oocyte, especially, lipid droplets that were surrounded by mitochondria and a large quantity of well-developed endoplasmic reticula appeared near the cortical layer (Fig. 3A).

\section{5) Late vitellogenic oocytes}

In the late vitellogenic stage, the early vitellogenic oocyte developed into the late vitellogenic oocytes. During the late vitellogenic oocyte, after a number of modified mitochondria appear in the cytoplasm of the late vitellogenic oocyte, and they are involved in formation of a number of multivesicular bodies by the structural changes of the mitochodrial cristae (Fig. 3B). In particular, in these oocytes, cortical granules appeared at the cortical region near the vitelline envelope. Especially, in this stage, exogenous yolk precursors, which

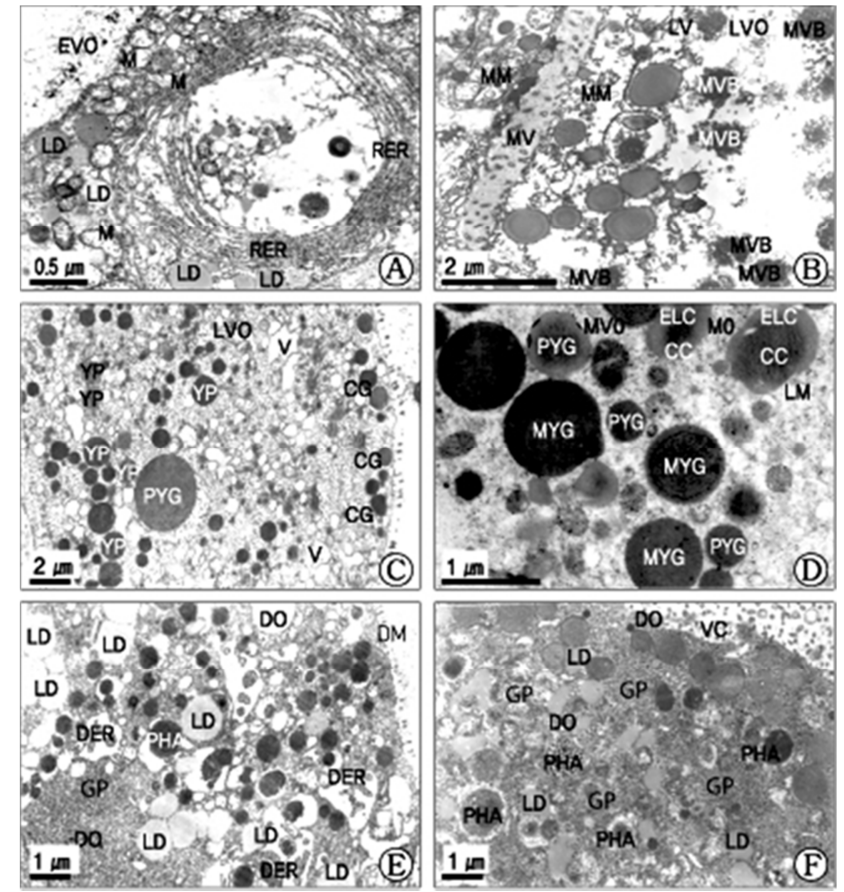

Fig. 3. Electron micrographs showing vitellogenesis and degeneration in the oocytes of Scapharca subcrenata (A-F). A, An early vitellogenic oocytes, with a number of lipid droplets near the mitochondria, endoplasmic reticulum in the cytoplasm; B, lipid droplets and glycogen particles in the germinal epithelium in the late vitellogenic oocytes, with modified mitochondria; $\mathrm{C}$, The late vitellogenic oocytes, detached follicle cells with lots of cortical granules in the cortical region; D, a late vitellogenic oocytes, with proteinaceous yolk granules, immature yolk granules and a number of mature yolk granules (the mature yolk granules were composed of three components; (1) a crystalline core, (2) an electronlucent cortex, and (3) a limiting membrane; E, F, degenerated oocytes, with a number of vacuoles, degenerating yolk granules, distended endoplasmic reticulum, a few phagosomes (lysosomes) and lipid droplets appeared in the cytoplasm. Abbreviations: $\mathrm{CC}$, crystalline core; DER, distended endoplasmic reticulum, DO, degenerated oocyte, EVO, early vitellogenic oocyte; GP, glycogen particle; LD, lipid droplet, LVO, late vitellogenic oocyte; M, mitochodrion; MM, modified mitochodrion; MV, microvillus; MVB, multivesicular body; MYG, mature yolk granule; PYG, primary yolk granule; 
PHA, phagosome; RER, rough endoplasmic reticulum; YP, yolk precursor.

was produced through the process of heterosynthetic vitellogenesis, were transferred into proteinaceous yolk granules. A number of yolk precursors, proteinaceous yolk granules, immature yolk granules lipid droplets, and yolk precursors appeared in the cytoplasm of the late vitellogenic oocyte (Fig. 3C). However, at this time follicle cells that were attached to the oocytes gradually lost their intimate association with the surface of the oocyte, and microvilli appeared along the vitelline envelope where the follicle cells had withdrawn.

\section{6) Mature oocytes}

In the mature stage, follicle cells that were attached to mature oocytes lost their intimate association with the surface of the oocyte, and microvilli appeared along the vitelline envelope where the follicle cells had withdrawn. In the mature oocytes, the thick vitelline envelope of the mature oocyte was slightly separated from follicular walls (the germinal epithelium). In the cytoplasm of the mature oocyte, small immature yolk granules continuously mixed with each other and became larger, mature yolk granules. The mature yolk granules were composed of three components: (1) a crystalline core, (2) an electron-lucent cortex, and (3) a limiting membrane. The vitelline envelope of the mature oocyte was approximately $0.45 \mu \mathrm{m}$ thick and was surrounded by a jelly coat (Fig. 3D).

\section{DISCUSSION}

In this study, the Golgi complex formed vacuoles and vesicles in the previtellogenic oocyte, as seen in other bivalves: M. edulis (Pipe, 1987), C. virginica (Eckelbarger and Davis, 1996), P. yessoensis (Chung et al., 2005) and $C$. (A.) farreri farreri (Chung, 2008). In the early vitellogenic oocyte, many authors (Pipe 1987; Dorange and Le Pennec, 1989; Gaulejac et al., 1995) suggested that the formation of lipid droplets occurred during vitellogenesis in oocytes in several species, however, no clear morphological evidence has yet been provided for the processes involved in lipid droplet formation. In the present study, lipid droplets appeared among the Golgi complex, well-developed endoplasmic reticulum, and mitochondria in the cytoplasm of the early vitellogenic oocytes. Therefore, it is assumed that various cell organelles may be involved in the formation of lipid droplets through the process of endogeneous autosynthetic vitellogenesis (Chung et al., 2005, 2008; Chung, 2007, 2008).

In particular, exogenous heterosynthetic vitellogenesis occurred in the early vitellogenic stage, several coated vesicles were present due to endocytosis, that appeared at the basal region of the oolemma of eraly vitellogenic oocytes, and prior to the formation of the vitelline envelope The uptake of nutritive material, that is, extraovarian precursors in coated vesicles occurred through the formation of coated pits on the oolemma during vitellogenesis (Eckelbarger \& Davis, 1996; Chung et al., 2005; Chung, 2008). Exogenous heterosynthetic vitellogenesis occurred through the incorporation of extraovarian precursors into oocytes by endocytosis before the formation of the vitelline envelope. From these findings, it is assumed that vitellogenesis in $P$. japonicus occur through the processes of endogenous autosynthetic and exogenous heterosynthetic vitellogensis. Thus, the processes of yolk formation by endogenous autosynthesis and exogenous heterosynthesis in $P$. japonicus are similar to those of C. virginica (Eckelbarger and Davis, 1996), $M$. edulis (Pipe, 1987), P. yessoensis (Chung et al., 2005), C. (A.) farreri farreri (Chung, 2008).

In particular, in these oocytes, cortical granules appeared at the cortical region near the vitelline envelope. Especially, in this stage, exogenous yolk precursors, which was produced through the process of heterosynthetic vitellogenesis, were transferred into proteinaceous yolk granules. A number 
of proteinaceous yolk granules, lipid droplets, and mitochondria appeared in the cytoplasm of the late vitellogenic oocyte. Thereafter, proteinaeceous yolk granules containing several different components combined and became larger immature yolk granules in the cytoplasm. However, at this time follicle cells that were attached to the oocytes gradually lost their intimate association with the surface of the oocyte, and microvilli appeared along the vitelline envelope where the follicle cells had withdrawn. Thereafter, proteinaeceous yolk granules containing several different components combined and became larger immature yolk granules in the cytoplasm. The activity of vitellogenic characteristics by endocytosis through microvilli along the vitelline envelope of the late vitellogenic oocytes was largely found in this stage because the formation of yolk granule materials were found by various cell organelles in the cytoplasm.

At the early developmental stage of oogenesis, the follicle cells at the periphery of the oogenic follicle (or acinus) initially appears close to the previtellogenic oocyte, and thereafter, progressively surrounds a part of the oocyte. In the early stage, a small number of vacuoles were visible in the cytoplasm of the follicle cells near the adherence zone. The attached follicle cells also showed cytological modifications as their cytoplasmic volume increased in the cells as shown in other bivalves: C. virginica (Eckelbarger and Davis, 1996) and M. edulis (Pipe, 1987). Because the follicle cells attach to the oocyte in the early stages of oogenesis and gradually detach from the vitellogenic oocyte, it is assumed that follicle cells function as nutritive cells in the early development of the oocytes (Chung et al., 2005; Chung, 2007). At this stage, a small number of vacuoles and a few myelin-like organelles were visible in the cytoplasm of the follicle cells near the adherence zone. The attached follicle cells showed progressive cytological modifications as their cytoplasmic volume increased in $C$. virginica (Eckelbarger and Davis, 1996) and M. edulis
(Pipe, 1987).

In the late stage of oogenesis, most follicle cells, which were attached to the late vitellogenic oocyte, were gradually decreased from the mid-or late vitellogenic oocytes; only a few cells appeared near the stalk region of the oocyte. At the adherence zone of the follicle cells-vitellogenic oocyte, lipid droplets were surrounded by the myelin-like organelles (myelin figures) in the cytoplasm of the oocytes. In particular, at this time, a number of vacuoles and myelinlike organelles appeared in the cytoplasm of the follicle cell, which was indicative of membrane brokedown, as seen in Mytilus edulis (Pipe, 1987). Pipe (1987) reported that endocytotic figures appeared between vitellogenic oocytes and the follicle cells, indicating a transfer of nutrients in M. edulis. In this study, similar ultrastructural changes have been observed in the follicle cells of this species. Follicle cells, which were attached to previtellogenic oocyte, showed the early developmental stage. At this time, in particular, glycogen particles, several vacuoles, and a few lipid droplets were visible in the cytoplasm of follicle cells attaching to previtellogenic oocytes. However, at the adherence zone of follicle cells and vitellogenic oocytes, several lipid droplets, myelin-like organelles (or myelin figures) and several number of vacuoles appeared in the cytoplasm of late vitellogenic oocytes. In particular, in the sexually ripe stage, a few follicle cells disappeared from the mature oocyte. Therefore, it is assumed that the follicle cells function as nutritive cells in the formation and development of the germ cells in their early stages as heterosynthetic vitellogenesis.

Regarding the functions of oocyte-follicle cells, we can describe as follows; In general, the follicle cells at the periphery of the oogenic follicle (or acinus) initially appears close to the previtellogenic oocyte in the early stages of oogenesis, and thereafter, The attached follicle cells also showed cytological modifications as their cytoplasmic volume increased in C. virginica (Eckelbarger and Davis, 
1996) and M. edulis (Pipe, 1987), and gradually detach from the vitellogenic oocyte, therefore, it is assumed that follicle cells function as nutritive cells in the early development of the oocytes (Chung et al., 2005; Chung, 2007). In this study, the number of lipid granules gradually increased in follicle cells during gametogenesis; this function can permit a transfer of yolk precursors necessary for vitellogenesis and allow for the accumulation of reserves in the cytoplasm as glycogen particles and lipids, which can be employed by vitellogenic oocytes (Gaulejac et al., 1995). In particular, a number of vacuoles, degenerating yolk granules, ditended endoplasmic reticulum, some phagosomes (or phagolysosomes lysosomes) are occurred (produced) by various lysosomes. In particular, a large number of lipid granules and a large amount of glycogen particles are reserved or accumulated in the cytoplasm of degenerated oocytes or degenerating follicle cells after the spawning period. These kinds of nutrients can be employed by vitellogenic oocytes for vitellogenesis and egg production.

\section{ACKNOWLDGMENTS}

This research was supported in part by the fund (2008) from Korea, Tnahae Fisheries Resources Institute.

\section{REFERENCES}

Chung EY (2007) Oogenesis and sexual maturation in Meretrix lusoria (Röding, 1798) (Bivalvia: Veneridae) in western Korea. J Shellfish Res 26:71-80.

Chung EY (2008) Ultrastructural studies of oogenesis and sexual maturation in female Chlamys (Azumapecten) Farreri Farreri (Jones \& Preston, 1904) (Pteriomorphia: Pectinidae) on the western coast of Korea. Malacologia 50:279-292.

Chung EY, Ko CH, Kang HW, Choi KH, Jun JC (2008)

Ultrastructure of oocytes during oogenesis and oocyte degeneration associated with follicle cells in female Sinonovacula constricta (Bivalvia: Pharidae) in western Korea. Animal Cells and Systerms 12:313-319.

Chung EY, Koh CH, Park GM (2007) Oogenesis, oocyte degeneration and sexual maturation in female Cyclina sinensis (Gmelin, 1971) (Bivalvia: Veneridae) in Korea Integrated Bioscience 11:191-198.

Chung EY, Park YJ, Lee JY, Ryu DK (2005) Germ cell differentiation and sexual maturation of the hanging cultured female scallop Patinopecten yessoensis on the east coast of Korea. J Shellfish Res 24:913-921.

Dorang G, Le Pennec M (1989) Ultrastructural study of oogenesis and oocytic degeneration in Pecten maximus from the Bay of St. Brieuc. Mar Biol 103:339-348.

Eckelvarger KJ, Davis CV (1996) Utrastructure of the gonad and gametogenesis in the eastern oyster, Crassostrea virginica. 1. Ovary and oogenesis. Mar Biol 127:79-87.

Gaulejac DB, Henry M, Vicente N (1995) An ultrastructural study of the marine bivalve Pinna nobilis (Linnaeus, 1758). 1. Oogenesis. J Mollusc Stu 6:375-392.

Kim JH, Chung EY, Choi MS, Lee KY, Lee IH, Seo WJ (2011) Germ cell differentiation during spermatogenesis, and ultrastructural characteristics of mature sperm in male Phacosoma japonicus (Bivalvia: Veneridae). Kor Malacol Soc 27:55-65.

Kwon OK, Park GM, Lee JS (1993) Coloured Shells of Korea. Academy Publishing Co., 288 pp. (in Korean)

Min DK, Lee JS, Ko DB, Je JG (2004) Mollusks in Korea. Hanguel Graphics. 566pp.

Pipe RK (1987) Oogenesis in the marine mussel Mytilus edulis: An ultrastructural study. Mar Biol 95:405-414.

Tanaka Y (1954) Spawning season of important bivalve in Ariake Bay Anadara subcrenata (Lischke). Bull Japan Soc Sci Fish 19:1157-1160.

Yoo JS (1976) Korean Shells in Collour. Ilgisa, Seoul, pp 196. (in Korean)

Yoo SK (1964) Biological studies on the propagation of 
important bivalve 1 Growth and size of adult bivalve of the Anadara subcrenata. Bull Nat'l Fish Univ Busan 6:15-20. (in Korean)

Yoo SK (1977) Biological studies on the propagation of important bivalve 5 morphological characteristics of the ark shell, Anadara subcrenata. Bull Nat'l Fish Univ Busan 17:71-78.

Yoshida H (1953) Studies on larvae and young shells of industrial bivalve in Japan. J Shimonoseki Coll Fish 3:15-18. (in Japanese) 